\title{
O papel do Ministério Público na autocomposição de conflitos sanitários transindividuais
}

The role of the Public Attorney's Office on the auto composition of transindividual sanitary conflicts

El rol del Ministerio Público en la autocomposición de conflictos sanitarios transindividuales

Lucineia Vieira Matos ${ }^{1}$

RESUMO: objetivo: analisou-se o papel do Ministério Público na autocomposição bilateral de conflitos sanitários transindividuais, envolvendo políticas públicas de saúde, notadamente se pode atuar como mediador, tendo em vista sua condição de parte, legitimado extraordinário pela substituição processual. Metodologia: tratou-se de estudo exploratório, de base qualitativa, desenvolvido a partir de fontes documentais primárias e bibliográficas, interpretadas e valoradas com os recursos da análise de conteúdo. Resultados: os resultados apurados indicaram que a adequada resolução de conflitos sanitários transindividuais, envolvendo direito à saúde e políticas públicas de saúde, perpassa por um sistema multiportas de acesso à Justiça, com primazia para a autocomposição bilateral, através da negociação, da mediação e da conciliação, de modo que o sistema de jurisdição somente seja acionado como último recurso. Emergiu, também, a legitimidade do Ministério Público para atuar nesse sistema, desempenhando distintos papéis na seara judicial e extrajudicial, tendo a observância ao ordenamento jurídico como linha condutora de sua atuação. Conclusão: na autocomposição bilateral de conflitos sanitários transindividuais, o Ministério Público atua como autêntico negociador colaborativo.

Palavras-chave: Direito à Saúde. Ministério Público. Judicialização da Saúde. Negociação.

ABSTRACT: objective: the role of the Public Attorney's Office on the bilateral auto composition of transindividual sanitary conflicts was analyzed, involving public policies of health, notably if it can act as a mediator bearing in mind its condition as a part, extraordinary legitimated by process substitution. Methodology: It was made in the way of an exploratory study, of qualitative basis, developed from primary and bibliographic documental resources on, interpreted and appraised with the resources of contain analysis. Results: the results ascertained indicated that the suitable resolution of the trans individual sanitary conflicts, involving the right to health and public health policies, overarches a multiple doors system, of access to justice with primacy to the bilateral auto composition, through the negotiation, the mediation and the conciliation in the way that the jurisdiction system is only activated as the final resource. So, is also emerged, the legitimacy of the Public Attorney's Office to act in that system, performing distinct roles in

\footnotetext{
${ }^{1}$ Promotora de Justiça do Ministério Público do Estado de Goiás. Brasil. Especialista em Direito Processual Civil. Email: lucineiavieiramatos@yahoo.com.br
} 
the judicial and extrajudicial field having the compliance to the legal order as the conducting line of its acting. Conclusion: On the bilateral auto composition of the transindividual sanitary conflicts, the Public Attorney's Office acts as an authentic collaborative negotiator.

Key Words: The right to health. Public Attorney's Office. Health judicialization. Negotiation.

RESUMEN: Objetivo: Se hizo un análisis del rol del Ministerio Público en la autocomposición bilateral de conflictos sanitarios transindividuales, envolviendo políticas públicas de salud, notablemente se puede actuar como mediador, teniendo en vista su condición de parte, legitimado extraordinario por la sustitución procesual. Metodología: Se ha tratado de estudio exploratorio, de base cualitativa, desarrollado a partir de fuentes documentales primarias y bibliográficas, interpretadas y valoradas con recursos de análisis de contenido. Resultados: los resultados apurados han indicado que la adecuada resolución de conflictos sanitarios transindviduales, envolviendo derecho a la salud, recorre por un sistema múltiples puertas de acceso a la justicia, con primacía para la autocomposición bilateral, a través de la negociación, de la mediación y de la conciliación, de modo que el sistema de jurisdicción solamente sea accionado como último recurso. Ha emergido, también, la legitimidad del Ministerio Público para actuar en ese sistema, desempeñando distintos roles en el campo judicial y extrajudicial, teniendo la observancia al ordenamiento jurídico como línea conductora de su actuación. Conclusión: en la autocomposición bilateral de conflictos sanitarios transindividuales, el Ministerio Público actúa como auténtico negociador colaborativo.

Palabras-Ilave: Derecho a la Salud. Ministerio Público. Judicialización de la Salud. Negociación.

\section{Introdução}

Vivenciamos o que Watanabe apresenta como fenômeno da "expansão do direito", aliado à "falência do Estado-Providência", que consagrou e ampliou direitos sociais sem o compromisso com a indispensável correspondência financeiro-orçamentária para concretizá-los (1).

Para maior complexidade do cenário, a inobservância da boa técnica legislativa propicia que, na falta de um consenso sócio-político, discipline-se açodadamente temas polêmicos e conflituosos, com normas legais imprecisas e desarmônicas.

Quando se trata do direito à saúde, a situação se agrava pela excessiva proliferação de atos normativos, distribuídos em inúmeros instrumentos, de diferentes fontes e origens políticas. No plano da gestão, a desarticulação e a dispersão de responsabilidades constituem uma dificuldade adicional (2). 
Daí que tais direitos não são concretizados ou, quando implementados, não o são de modo integral, gerando complexos conflitos, cuja instância final de garantia e pacificação é o Poder Judiciário.

Salles identifica nesse contexto um novo modelo de litigância civil, cujo objeto "é vindicar a efetivação de políticas públicas expressas em lei ou decorrentes de valores consagrados constitucionalmente." Trata-se, na visão do processualista, da aplicação do conceito aristotélico de justiça distributiva, na medida em que a atuação do Poder Judiciário importa na alocação e repartição de recursos públicos (3).

Para Barroso, "significa que algumas questões de larga repercussão política e social estão sendo decididas por órgãos do Poder Judiciário, e não pelas instâncias políticas tradicionais: o Congresso Nacional e o Poder Executivo" (4).

Por aí perpassa a judicialização do direito à saúde, impondo ao Poder Judiciário e aos seus juízes a vivência de dilemas para os quais não foram preparados e a adoção do que Delduque e Marques denominaram "decisões trágicas” (5).

Reconhece-se que a atuação do Poder Judiciário contribuiu para a concretização do direito à saúde e, em menor grau, para a definição de políticas públicas. Porém, atuando sob os critérios da microjustiça, privado do olhar sobre o todo, provoca graves distorções no Sistema Único de Saúde e comprometimento de sua complexa execução financeiro-orçamentária. Tornou-se excessiva e é fonte de permanente tensão entre os Poderes (2).

Embora se caminhe no sentido da coletivização da tutela, com a introdução de novos instrumentos no ordenamento jurídico, a exemplo da ação civil pública, fato é que a mentalidade formada pela teoria clássica de orientação liberal ainda constitui limitação para compreensão e eficácia dos direitos transindividuais (2).

Noutra ponta, os custos implicados na defesa administrativa, judicial e política desses novos direitos são elevados, mormente se comparados à parcela de interesse individual correspondente. O resultado é uma tendência de imobilismo do cidadão e das organizações não governamentais, alçando o Ministério Público, em função de sua especialização e da sua configuração constitucional, à condição de protagonista no manejo da ação civil pública e, pois, no patrocínio da defesa dos direitos transindividuais (6). 
Conquanto a tutela dos interesses difusos e coletivos seja um fim que o Ministério Público não pode deixar de perseguir, é "perfeitamente possível seja ele alcançado a partir de uma pluralidade de percursos distintos, que não passam, necessariamente, pela judicialização da atuação" (7).

Não por outra razão, o Conselho Nacional do Ministério Público editou a Resolução no 118 , de $1^{\circ}$ de dezembro de 2014, dispondo sobre a Política Nacional de Incentivo à Autocomposição no âmbito do Ministério Público (8), bem como a Recomendação nº 54, de 28 de março de 2017, que dispõe sobre a Política Nacional de Fomento à Atuação Resolutiva do Ministério Público Brasileiro (9).

A recepção dessa nova cultura deu lugar ao $3^{\circ}$ do artigo $3^{\circ}$ no novo Código de Processo Civil (10), dispondo que a conciliação, a mediação e outros métodos de solução consensual de conflitos deverão ser estimulados por juízes, advogados, defensores públicos e membros do Ministério Público, inclusive no curso do processo judicial.

Na sequência, veio a Lei nำ13.140, de 26 de junho de 2015, que dispõe sobre a mediação entre particulares e a autocomposição de conflitos no âmbito da administração pública (11).

No campo do Direito Sanitário, observa-se um esforço tendente a buscar caminhos que propiciem e facilitem a interlocução direta entre o usuário e o Sistema Único de Saúde, na construção de soluções negociadas, reduzindo a participação do Poder Judiciário como instância intermediária (2).

Como contribuição, buscou-se analisar o emprego de meios autocompositivos bilaterais pelo Ministério Público na resolução de conflitos sanitários metaindividuais. Para tanto, fez-se investigação orientada pela pergunta: O Ministério Público, tendo em vista sua condição de parte, como substituto processual, pode ser mediador de conflitos sanitários coletivos?

\section{Metodologia}

Tratou-se de estudo exploratório, de base qualitativa, desenvolvido a partir de fontes documentais primárias e bibliográficas, constituídas pela Constituição Federal, leis, resoluções, recomendações, bem como produção científica e intelectual. As bases de dados legislativas consultadas foram os sítios web da Presidência da República - 
Acervo - Legislação - e do Conselho Nacional do Ministério Público (CNMP) - Atos e Normas. A pesquisa nessas bases deu-se no período de junho a outubro de 2017 e foram utilizados os descritores "constituição", "códigos", "código de processo civil", "código de defesa do consumidor", "ministério público", "mediação", "ação civil pública”, "notícia de fato", "inquérito civil", "audiências públicas", "compromisso de ajustamento de conduta", "autocomposição", "resolutividade".

Para a pesquisa bibliográfica foram selecionados, por critério de oportunidade, e consultados, livros e artigos sobre os temas: "ministério público", "processo civil de interesse público", "processo coletivo", "ação civil pública”, "ações coletivas”, "políticas públicas e judiciário", "direito sanitário", "judicialização da saúde”, "termo de ajustamento de conduta", "interesses difusos e coletivos", "mediação", "mediação sanitária", "pesquisa social". As bases de dados científicos consultadas foram identificadas através do sítio de busca Google acadêmico. A pesquisa nessas bases deu-se no período de agosto a outubro de 2017 e foram utilizados, além dos descritores temáticos, os seguintes: "resolução colaborativa de disputas", "judicialização das políticas públicas", "direitos transindividuais".

Após reunião do material de consulta e leitura sistematizada, os dados foram organizados em fichas de apontamentos para interpretação e valoração à luz dos objetivos definidos no projeto de pesquisa, com auxílio da metodologia da Análise de Conteúdo (12).

\section{Resultados e Discussão}

A pesquisa documental resultou na identificação de treze fontes, ordenadas sequencialmente, por número e tema, de acordo com seu emprego neste tópico, conforme Quadro 1 abaixo.

A Constituição Federal de 1988 (13) estruturou o Ministério Público (art. 127), incumbindo-lhe a defesa da ordem jurídica, da democracia e dos interesses sociais e individuais indisponíveis. A instituição finalmente rompeu seu vínculo de representação do Executivo, ganhando uma nova feição, voltada para a defesa proativa dos interesses mais caros da sociedade. 
Entre suas funções está a de zelar para que os poderes públicos e os serviços de relevância pública respeitem e cumpram os direitos que a própria Constituição assegura às pessoas, promovendo, para tanto, as medidas judiciais e extrajudiciais que se fizerem necessárias (art. 129, II).

As ações e serviços públicos de saúde foram considerados pela Constituição como sendo de relevância pública (art. 197).

O direito à saúde, por seu turno, inserto no art. 6ª alocado no capítulo que trata dos direitos sociais, compõe o título dos direitos e garantias fundamentais. Corolário que é do direito à vida e partilhado por um número indeterminável de indivíduos, a saúde ora se apresenta como direito difuso, ora como direito individual indisponível.

Da Constituição ainda se extrai a competência do Ministério Público para promover o inquérito civil e a ação civil pública ${ }^{2}$, na defesa do patrimônio publico e social, do meio ambiente e de outros interesses difusos e coletivos, aqui se incluindo a saúde.

Por óbvio, a Constituição não esgota todas as possibilidades de atuação do Ministério Público, o que nos remete à sua Lei Orgânica Nacional, Lei 8.625/1993 (14), à Lei Orgânica do Ministério Público da União, Lei Complementar 75/1993 (15) e às Leis Orgânicas Estaduais.

Entre as atribuições fixadas na Lei Orgânica Nacional do Ministério Público (14), merecem destaque as de natureza não judicial, como a expedição de recomendações e promoção de audiências públicas (art. 27, parágrafo único). Nesse passo, determina que seus representantes atendam a qualquer do povo, tomando as providências cabíveis (art. 32, II). A facilitação do diálogo entre o cidadão e o Ministério Público representa importante garantia de acesso à justiça, mesmo porque, ordinariamente, as demandas chegam às Procuradorias e Promotorias através do atendimento ao público, sem prejuízo do acolhimento de representações, requerimentos e documentos ou, ainda, da atuação por iniciativa própria do Promotor ou Procurador.

Faz-se o registro, como notícia de fato, em sistema informatizado de controle (16). Não sendo arquivada de plano ou solucionada no prazo fixado, reclamando outras providências, será objeto de procedimento próprio: procedimento administrativo para

2. Pontua-se, contudo, que desde 1985, a Lei da Ação Civil Pública (Lei 7.347/85) já legitimava Ministério Público ao patrocínio dos direitos difusos, coletivos e individuais homogêneos. E, antes disso, a Lei 6.938/1981, que instituía a Política Nacional de Meio Ambiente. 
acompanhamento e fiscalização ou apuração de fato que enseje tutela de direito individual indisponível; inquérito civil público para investigação de fatos que possam autorizar a tutela de direitos transindividuais (17).

No âmbito de tais procedimentos extrajudiciais é que se realizam audiências públicas (18), expedem-se recomendações (17) e tomam-se dos interessados compromissos de ajustamento de condutas (19), três importantes instrumentos de atuação resolutiva do Ministério Público e produção de resultados socialmente relevantes fora do processo judicial (9).

Tendo-se apropriado da disciplina legal do Ministério Público, avança-se sobre a temática dos direitos transindividuais.

Em nosso ordenamento jurídico, vem do Código de Defesa do Consumidor (21) a definição das categorias que se reúnem no gênero direitos transindividuais. Dita seu art. 81, parágrafo único, inciso I, que são difusos os direitos transindividuais "de natureza indivisível, de que sejam titulares pessoas indeterminadas e ligadas por circunstância de fato". No inciso II conceitua como coletivos os direitos transindividuais "de natureza indivisível de que seja titular grupo, categoria ou classe de pessoas ligadas entre si ou com a parte contrária por uma relação jurídica base". Por fim, no inciso III, diz dos "direitos individuais homogêneos, assim entendidos os decorrentes de origem comum".

Cumpre agora buscar o tratamento legal dos meios autocompositivos, restringindose aos bilaterais, facilitados ou não, a saber: mediação, conciliação e negociação. Todos têm em comum, na sua essência, a ausência de uma decisão imposta por terceiro. $O$ conflito é solvido pelos próprios envolvidos (22).

Dois diplomas legais tratam da mediação no ordenamento jurídico brasileiro, o Código de Processo Civil (10) e a Lei n. 13.140/2015 (11). Não se considera relevante, para o fim deste estudo, aprofundamento sobre vigência, aplicação e interação entre as normas. Aplica-se a tese do "diálogo das fontes" para reconhecer a complementariedade dos instrumentos normativos (23).

Assim é que, após a edição da Lei n. 13.140/2015 (11), nosso ordenamento jurídico incorporou um conceito de mediação:

Considera-se mediação a atividade exercida por terceiro imparcial sem poder decisório que, escolhido ou aceito pelas partes, as auxilia e estimula a identificar ou desenvolver soluções consensuais para a controvérsia. (Art. 1ํㅡ, Parágrafo único). 
O Código de Processo Civil (10) fez distinção expressa com a conciliação, ao determinar diferentes adequações e posturas na condução do processo para cada um dos meios: enquanto o conciliador assume postura mais ativa em busca do consenso, preferencialmente quando não há vínculo anterior entre os envolvidos, o mediador atua nos casos de relações continuadas, assumindo papel de facilitador, auxiliando as partes a compreender o conflito e restabelecer a comunicação, de modo a identificar, por si próprias, soluções consensuais e mutuamente benéficas (art. 165, $\S \S 2^{\circ}$ e $3^{\circ}$ ).

A mediação em nosso sistema (11), identificada como adepta da escola linear de Harvard, cujo escopo é a solução do conflito pelo acordo (22), é orientada pelos princípios da imparcialidade do mediador, isonomia entre as partes, oralidade, informalidade, autonomia da vontade das partes, busca do consenso, confidencialidade e boa-fé (art. $\left.2^{\circ}\right)$.

Embora a lei (11) diga que poderá funcionar como mediador extrajudicial qualquer pessoa capaz que tenha a confiança das partes (art. 9º), o que se percebe na análise do texto normativo é que a mediação é tratada como uma atividade técnica, regulada e, em certo ponto, judicializada (24).

Nesse sentido e para o fim de atender ao princípio da imparcialidade, aplicam-se ao mediador as mesmas hipóteses legais de impedimento e suspeição do juiz.

Ademais, segundo a lei (11), o mediador fica impedido, pelo prazo de um ano, contado do término da última audiência em que atuou, de assessorar, representar ou patrocinar qualquer das partes (art. 6을.

Pode ser objeto de mediação qualquer conflito sobre direitos disponíveis ou indisponíveis, mas transigíveis; neste caso, exige-se homologação judicial após oitiva do Ministério Público (art. $3^{\circ}$ ), sendo esta a única atribuição conferida à instituição pela Lei da Mediação.

O termo final da mediação, alcançada a composição, constitui título executivo (art. 20, Parágrafo único).

A lei (11) também contempla a autocomposição de conflitos em que é parte pessoa jurídica de direito público. Recomenda a criação de câmaras, inclusive para dirimir conflitos com particulares (art. 32, II). Aqui se identifica o permissivo legal para uso da 
mediação na resolução de demandas por ações e serviços de saúde, incluindo a dispensação de medicamentos e a realização de exames e procedimentos.

Quanto à aplicação da mediação para resolução de conflitos transindividuais, o tratamento legal é pífio. Limitou-se a dizer, em seu art. 33, Parágrafo único (11), que a Advocacia Pública poderá instaurar, de ofício ou mediante provocação, procedimento de mediação coletiva de conflitos relacionados à prestação de serviços públicos.

Embora o dispositivo permita o acolhimento da mediação sanitária em conflitos metaindividuais, questiona-se a imparcialidade do mediador que conduzirá o procedimento, patrocinando, ao mesmo tempo, os interesses de uma das partes, o ente público envolvido (25). Nem sempre o interesse primário da sociedade se harmoniza com o interesse secundário da pessoa jurídica de direito público.

Neste caso, à vista do art. 6ำ (11), frustrado o acordo, o Advogado Público que conduziu o processo de mediação ficará impedido de representar o ente público em juízo, o que pode se revelar contraproducente para pequenos municípios que dispõem de poucos ou somente um Procurador.

No Ministério Público a mediação é recomendada para solucionar controvérsias em torno de relações jurídicas colaborativas, a exemplo das relações comunitárias e escolares. Observa-se da Resolução editada pelo Conselho Nacional de Ministério Público que a mediação é empregada na composição de conflitos em que o Ministério Público pode intervir, mas não é parte, sem prejuízo de que suas técnicas possam subsidiar a atuação em geral, facilitando a comunicação, prevenindo e solucionando conflitos interpessoais (8).

Disciplinada pelo Código de Processo Civil (10), a conciliação é indicada nos casos em que não há vínculo anterior entre os litigantes (art. 165, §2). Aqui o conciliador pode sugerir soluções para o litígio. No mais, rege-se pelos mesmos princípios norteadores da mediação (art. 166).

Embora o emprego da conciliação tenha se consolidado entre nós como um fenômeno processual e ainda constitua uma fase do processo civil (art. 319, VII e 334), fato é que o novo Código (10) prevê sua aplicação, ao lado da mediação, também, por conciliadores privados (art. 168). 
Importante destacar que, segundo a nova disciplina legal (10), a preferência pela condução da audiência conciliatória ou de mediação não é mais do juiz, que atua somente onde não houver conciliador ou mediador. Vê-se nisso um avanço no sentido de preservar a imparcialidade do órgão julgador, que pode se ver influenciado em seu julgamento pelo conteúdo das tratativas frustradas de composição. Noutra ponta, sua presença pode impedir a franqueza das partes no diálogo, receosas da exposição de fatos e posições comprometedoras num futuro julgamento (26).

No âmbito do Ministério Público, a conciliação é indicada para solução de conflitos que envolvam direitos ou interesses nas áreas de atuação do órgão como interveniente, ou seja, em processos judiciais quando não é parte e atua como fiscal da ordem jurídica. Nada impede, porém, que, nas mesmas condições, seja empregada extrajudicialmente (8).

Não há lei específica sobre negociação, tema comumente afeto às relações de trabalho. O Código de Processo Civil (10) menciona em seu art. 165, §3ª aplicação de técnicas negociais com o objetivo de favorecer a autocomposição.

A lei de mediação (11) também se refere ao emprego da negociação na mediação extrajudicial (art. 21).

Não obstante, o Conselho Nacional do Ministério Público disciplinou a negociação como prática autocompositiva no âmbito do Ministério Público, recomendando-a para resolução de conflitos e controvérsias sobre direitos difusos e coletivos, em que a instituição é legitimada a atuar como parte, na defesa da sociedade (8).

O compromisso de ajustamento de conduta, previsto na Lei 7.347/85 (20) e disciplinado pela Resolução CNMP 179/2017 (19) é o instrumento por excelência de negociação ministerial. Tem, pois, natureza de negócio jurídico e visa à redução de litigiosidade pela adequação da conduta do compromissário às exigências legais e constitucionais, com eficácia de título executivo extrajudicial.

A pesquisa bibliográfica, por sua vez, resultou na seleção de vinte e cinco referências, ordenadas sequencialmente por autor e título, de acordo com seu emprego no texto, conforme Quadro 2 abaixo.

Em busca de soluções adequadas para os conflitos sanitários, verificou-se da pesquisa bibliográfica que os direitos transindividuais, difusos, coletivos e individuais 
homogêneos, surgem da necessidade de proteção a direitos que transcendem a esfera do indivíduo para alcançar uma coletividade ou comunidade, em superação à dicotomia público-privado. Não pertencem à Administração Pública, tampouco ao indivíduo particularmente considerado. São os chamados direitos fundamentais de terceira dimensão ou geração, que impõem uma nova lógica ao sistema de tutela judicial e extrajudicial (27).

O que diferencia os direitos coletivos dos difusos é a determinabilidade de seus titulares, decorrente da vinculação a um determinado grupo, categoria ou classe, ou seja, nos direitos coletivos, a despeito da indivisibilidade, é possível determinar seus titulares, o que não ocorre nos difusos (28). São coletivos, por exemplo, os direitos dos segurados de determinado plano de saúde, vinculados por uma relação jurídica contratual, enquanto os direitos dos usuários do SUS, vinculados apenas pela circunstância fática de encontrarem-se no Brasil, são considerados difusos, pela indeterminabilidade de seus titulares.

Vale a advertência: "não se trata de um somatório de interesses individuais, mas sim de um novo interesse que pertence a muitos ou a um grupo, sem que pudesse ter fruição individual" (29).

Quanto aos direitos individuais homogêneos, identifica-se em sua natureza jurídica uma ficção criada pela lei, a fim de permitir a tutela coletiva (30).

De fato, o tratamento coletivo das pretensões apresenta vantagens evidentes: evita a proliferação de causas individuais e soluções divergentes para a mesma questão, além de ampliar o acesso à justiça nas causas em que o ganho pessoal, ínfimo, desestimula o acionamento do Judiciário.

O Ministério Público é um dos legitimados ao patrocínio judicial de tais direitos, atuando como parte, na condição de substituto processual. Sua legitimação, neste caso, decorre da lei e é tida como extraordinária porque não é titular do direito posto em juízo. Embora aja em nome próprio, defende interesses alheios (28).

Deve-se admitir, contudo, que o aparato judicial não tem se mostrado o mais eficaz para resolução de conflitos envolvendo direito difuso, coletivo ou individual homogêneo à saúde, por sua complexidade. 
Os conflitos em torno das políticas públicas de saúde são policêntricos, a significar que a decisão proferida num processo judicial afeta um sem número de pessoas que dele não participaram, notadamente quando repercute de forma negativa sobre o uso adequado dos recursos disponíveis (31).

Assim, a solução judicial perde a primazia, passando a ultima ratio. Busca-se agora o acesso aos direitos pela via mais adequada de composição. Essa visão retira dos meios autocompositivos o selo da alternatividade, trazendo a compreensão de que serão legítimos na medida em que forem adequados ao fim proposto (28).

Está-se diante de um sistema multiportas, que põe à disposição dos interessados a possibilidade de dirimir seus conflitos por diferentes meios, que coexistem e interagem (23). Para explicar o fenômeno, propõe-se o seguinte organograma.

(Figura 1)

Embora esse movimento tenha ocorrido a partir da tutela dos direitos individuais, não há dúvida de que se amolda à tutela dos direitos coletivos lato sensu (32), inclusive do direito à saúde.

O primeiro passo nesse sentido é flexibilizar o parâmetro segundo o qual o interesse público não pode ser objeto de negociação. Especialmente quando é definido por conceitos jurídicos indeterminados e normas abertas, permitindo a aferição de graus e o preenchimento de lacunas no caso concreto, com certa margem de disponibilidade, sempre buscando a tutela mais harmônica e abrangente, sob o crivo da motivação (28).

Resumem-se a duas as regras do trato extrajudicial de conflitos envolvendo direitos transindividuais e, por conseguinte, indisponíveis: não pode haver renúncia, nem concessão do direito; a vontade, ao final manifesta, deve coincidir com o interesse de seus titulares, o que pode ser aferido por consulta e/ou por presunção, no caso da representação adequada por substituição, como se dá com o Ministério Público (29), que atua como "autêntico negociador" (33), compondo diretamente com o responsável pela violação - ou ameaça de violação - ao direito, a melhor solução jurídica, permeada pela interdisciplinariedade.

As negociações se concentram, pois, em torno da forma, do prazo e das condições de atendimento do direito difuso em jogo (29). 
Define-se a negociação como método ou técnica de comunicação direta entre as partes envolvidas no conflito, que vão alterando suas posições e exigências até alcançarem um compromisso juridicamente aceitável e exequível para todos (26). Tratase do "mais fluido, básico e elementar meio de resolver controvérsias, e também o menos custoso" (23).

Fala-se aqui da negociação cooperativa, baseada na máxima do "ganha-ganha", na qual o negociador mantém-se atento a possibilidades inovadoras, criação de valor e preservação de relacionamentos. O modelo competitivo revela-se inadequado pela atitude do negociador, cujo foco é obter a maior vantagem possível sobre o outro: "ganha-perde" (23).

Tartuce (23), valendo-se dos ensinamentos de Fischer e Ury, indica os princípios informadores da negociação:

[...] não negociar sobre posições (geralmente fechadas), mas considerar os interesses; separar as pessoas dos problemas (tratando os outros sempre com respeito, confiança e consideração); fixar-se nos reais interesses envolvidos (desejos e preocupações) e não nas posições formais adotadas (de rigidez ou conduta fechada); imaginar, criativamente, opções alternativas, com ganhos recíprocos.

Assim é que, antes de judicializar políticas públicas de saúde, sem prejuízo da expedição de recomendações, o Ministério Público pode mobilizar os diversos atores sociais em torno da problemática, agregando forças e funcionando como um canal de comunicação/negociação entre usuários e gestão.

Isso se dá, rotineiramente, por meio de reuniões e audiências públicas. A audiência pública, como mecanismo de escuta qualificada, permite o conhecimento mais aprofundado das demandas sociais e da situação a ser ajustada e auxilia na escolha da melhor opção entre as juridicamente possíveis, qualificando posterior compromisso de ajustamento de conduta como instrumento de redução da litigiosidade (18).

No dizer de Cambi:

"[...] permite o uso rawlsiano da razão pública, com a construção de critérios e motivações jurídicas, concebidas de modo objetivo e racional, na medida em que são compartilhados após serem compartilhadas outras concepções, experiências e mundividências que integram o pluralismo razoável, próprio das sociedades abertas e democráticas" (34). 
Como bem pontua Godinho, "a moderna atividade do Ministério Público não se coaduna com uma postura burocrática, limitada ao exame de papéis dentro de um gabinete" (35).

Esse modelo de atuação extrajudicial, também denominado "resolutivo", em oposição ao "demandista", que transfere suas demandas ao Poder Judiciário (33), para Ribeiro constitui função administrativa, cujo atributo é a discricionariedade.

A discricionariedade nas atribuições do Ministério Público faz-se presente quando, diante do caso concreto, é dado ao membro do Parquet a possibilidade de apreciar a circunstância fática que lhe impõe a atuação, segundo critérios de oportunidade e conveniência, e escolher uma dentre duas ou mais soluções, todas válidas para o direito (36).

Sendo a discricionariedade um "comando de otimização", reclama limites. Elege, pois, o autor filtros depuradores da atuação ministerial discricionária, dentre os quais se destaca a legalidade, a finalidade, a motivação, a procedimentalidade, a proporcionalidade, a adequação, a mínima intervenção ou mínima lesão e a segurança jurídica (36).

Ribeiro compreende a legalidade para além do aspecto formal de correspondência com a lei, no sentido de legitimidade, extraída da conformidade com o estatuto fundamental do Estado Democrático de Direito: a Constituição.

A finalidade prende-se ao interesse público protegido pela norma, que no dizer de Souto "deve ser visto como o interesse primário, da sociedade, que, na era do pluralismo e da complexidade dos fenômenos sociais, resultará de um processo de harmonização" (37).

Já a motivação nos remete à teoria dos motivos determinantes, que permite o exame dos fundamentos de fato e de direito, orientadores do ato praticado.

A procedimentalidade, requisito intrínseco da motivação, constitui o próprio desenrolar do processo em todas as suas fases, que devem ser registradas e justificadas, possibilitando ao cidadão conhecimento prévio dos passos a serem seguidos.

A par da motivação, alcança-se o próximo filtro, que é a proporcionalidade entre os meios empregados e o fim almejado. Nessa esteira, ainda se identificam a adequação e a mínima lesão. Impõe-se ao órgão ministerial a escolha do meio mais eficaz, dentre os 
considerados aptos, que importe na máxima satisfação do objetivo pretendido com a produção do menor agravo a outros interesses.

Por fim, a segurança jurídica, a exigir que o Ministério Público adote posicionamento semelhante em situações equivalentes (36).

Imperioso ressaltar, contudo, que a parametrização da discricionariedade conferida ao Ministério Público deve guardar harmonia com a essência do Estado Democrático de Direito e, por conseguinte, preservar a garantia de independência funcional dos seus membros, de modo que não venha a se impor como instrumento de manietar sua atuação (38).

Quando há indícios, porém, de que as partes romperam os canais de comunicação e se revelam incapazes de compor, por si mesmas, uma resposta adequada ao conflito, recomendável a participação de um terceiro facilitador imparcial. É onde se insere a conciliação e a mediação.

Souza (32) defende que a instituição de norma específica sobre o uso da mediação na solução de conflitos coletivos seria resposta eficaz à inadequação do sistema jurisdicional para responder à complexidade dos conflitos desta natureza, tanto do ponto de vista técnico-científico, quanto do intersubjetivo.

A primeira adaptação reclamada diz respeito à confidencialidade; na mesma medida em que se justifica na gestão dos conflitos individuais, a exemplo das questões de família, não se legitima quando envolve direitos de dimensão coletiva. A presença de entes públicos, como parte do conflito ou como regulador da política estatal, subordinados que estão ao dever legal de publicidade de seus atos, provoca a inversão do princípio, de modo que o sigilo passa a ser exceção e, portanto, deve ser justificado (32).

A informalidade e a oralidade também demandam certa flexibilização, no sentido de que as várias etapas de participações devem ser objeto de registro, em função mesmo da complexidade e do número de participantes, para que não se percam contribuições relevantes.

As etapas do processo de mediação coletiva podem se desenvolver na seguinte ordem: definição do contexto em que se insere o conflito ou a ameaça de lesão e identificação dos grupos e entes públicos interessados; planejamento da série de 
mediação, com definição de agenda, regras de participação e necessidade de estudos técnicos; realização das sessões, começando por esclarecimentos sobre o método, compartilhamento de informações para o diagnóstico do conflito, definição de interesses legítimos; fomento de opções para composição, o que pode se dá, a depender da complexidade, com a realização de oficinas temáticas em grupos e retorno ao plenário; e finalização com a construção de uma solução aceita por todos e passível de cumprimento. Durante o processo o mediador deve assegurar a representatividade dos participantes e cuidar para que a redação do acordo seja clara, precisa e com previsão de sanções para descumprimento. Ao final, recomenda-se que o processo seja avaliado pelos participantes, no sentido de aprimorar a técnica (32).

Nesse roteiro se insere a mediação sanitária, no tocante às políticas públicas de saúde, pontuando-se, desde logo, a grande dificuldade de operacionalização, pela falta de mediadores capacitados neste tipo de conflito.

\section{Conclusão}

O Ministério Público tem o poder-dever de atuar sempre que as ações e serviços ofertados pelo Sistema Único de Saúde, de algum modo, conflitarem com o direito transindividual à saúde, constitucionalmente assegurado; também, quando o Poder Público, por ação comissiva ou omissiva, causar lesão ao direito público subjetivo à saúde, bem da vida que lhe é dever tutelar.

Sua atuação pode ser judicial (demandista) e extrajudicial (resolutiva). Esta deve preferir àquela, sempre que adequada ao fim almejado.

$\mathrm{Na}$ esfera judicial deve priorizar, como parte, as ações coletivas em detrimento das individuais, pela eficácia ampliada da coisa julgada; como fiscal da ordem jurídica, em demandas propostas por outros legitimados, deve valer-se das técnicas de conciliação e mediação, a fim de fomentar o acordo entre os envolvidos, sem perder de vista 0 interesse que motivou sua intervenção.

$\mathrm{Na}$ seara extrajudicial, considerando que o direito, embora indisponível, é transigível, deve assumir o protagonismo da negociação colaborativa, no âmbito do compromisso de ajustamento de conduta, precedido, quando necessário para o aprimoramento dos termos e condições, de audiência pública, com escuta qualificada, intersetorial e interdisciplinar. 
Reconhece-se no compromisso de ajustamento de conduta importante função preventiva de litígios, pela possibilidade de se dispor para o futuro, não se limitando à resolução do conflito presente.

Embora não falte ao Ministério Público disposição para mediar, entende-se que sua posição de substituto processual e, pois, parte, na tutela do direito transindividual à saúde, desqualifica-o como mediador imparcial. Sem prejuízo, reconhece-se que se apropria de vários recursos da mediação em suas relações e pode assumir o papel de mediador, quando destituído da condição de parte, a exemplo da mediação comunitária e escolar.

Nada impede, também, que participe do processo de mediação conduzido por outrem, na condição de parte interessada.

Admite-se que possa funcionar como conciliador, extrajudicialmente, em conflitos envolvendo demandas individuais de saúde em face do ente público, sendo recomendável neste caso que, frustrada a autocomposição, não atue judicialmente como substituto processual do usuário. Embora o direito subjetivo seja indisponível e, por conseguinte, não comporte renúncia, seu exercício constitui faculdade do titular, cujo patrocínio em juízo deve se dar por Advogado ou por Defensor Público, a evitar eventual uso de informações privilegiadas, obtidas pelo órgão ministerial durante o processo frustrado de conciliação extrajudicial.

Imperioso rememorar que as soluções ajustadas pelo Ministério Público em autocomposição sanitária transindividual, por não contar com a participação direta dos titulares do direito negociado, somente se legitimam havendo consenso válido e harmonização com o ordenamento jurídico, sobretudo com a ordem constitucional (33).

\section{Referências}

1. Watanabe K. Processo civil de interesse público: introdução. In: Salles, CA, organizador. Processo Civil e interesse público: o processo como instrumento de defesa social. São Paulo: Editora Revista dos Tribunais, Associação Paulista do Ministério Público; 2003. p.15-21.

2. Bucci MPD. Contribuição para a redução da judicialização da saúde: uma estratégia jurídico-institucional baseada na abordagem de direito e políticas públicas. In: Bucci MPD, Duarte CS, coordenadoras. Judicialização da saúde: a visão do Poder Executivo. São Paulo: Saraiva; 2017. p. 31-88. 
3. Salles CA. Processo civil de interesse público. In: Salles, CA, organizador. Processo Civil e interesse público: o processo como instrumento de defesa social. São Paulo:

Editora Revista dos Tribunais, Associação Paulista do Ministério Público; 2003. p. 39-77.

4. Barroso LR. Judicialização, ativismo judicial e legitimidade democrática. Cadernos (Syn)thesis. 2012, 5 (1): 23-32. Disponível em: http://www.e-

publicacoes.uerj.br/index.php/synthesis/article/view/7433/5388. [Acesso em: 24.set.2017].

5. Delduque MC, Marque SB. O direito social à saúde deve ser garantido por políticas públicas e decisões judiciais. In: Delduque MC, organizadora. Temas atuais de Direito Sanitário. Brasília: Ministério da Saúde, Fundação Oswaldo Cruz; 2009. p. 121-128.

6. Salles CA. A proteção judicial de interesses difusos e coletivos: funções e significados. In: Salles, CA, organizador. Processo Civil e interesse público: o processo como instrumento de defesa social. São Paulo: Editora Revista dos Tribunais, Associação Paulista do Ministério Público; 2003. p. 131-137.

7. Garcia E. Ministério Público: organização, atribuições e regime jurídico. 6.ed. São Paulo: Saraiva; 2017. p. 463-464.

8. Brasil. Conselho Nacional do Ministério Público. Resolução nำ118, de $1^{\circ}$ de dezembro de 2014. Dispõe sobre a Política Nacional de Incentivo à Autocomposição no âmbito do Ministério Público. Diário Oficial de União. Brasília, 27 jan 2015. Disponível em http://www.cnmp.mp.br/portal/images/Normas/Resolucoes/Resolu\%C3\%A7\%C3\%A3o_n \%C2\%BA_118_autocomposi\%C3\%A7\%C3\%A3o.pdf [Acesso em 24.set.2017].

9. Brasil. Conselho Nacional do Ministério Público. Recomendação no 54, de 28 de março de 2017. Dispõe sobre a Política Nacional de Fomento à Atuação Resolutiva do Ministério Público brasileiro. Diário Eletrônico do CNMP, Brasília, 19 abr 2017. Disponível em http://www.cnmp.mp.br/portal/atos-e-normas/norma/4891 [Acesso em 3.set.2017].

10. Brasil. Lei no 13.105, de 16 de março de 2015. Código de Processo Civil. Diário Oficial de União. Brasília, 17 mar 2015. Disponível em: http://www.planalto.gov.br/ccivil_03/_ato2015-2018/2015/lei//13105.htm\#art1045 [ Acesso em 24.set.2017].

11. Brasil. Lei no 13.140, de 26 de junho de 2015. Dispõe sobre a mediação entre particulares como meio de solução de controvérsias e sobre a autocomposição de conflitos no âmbito da administração pública. Diário Oficial da União. Brasília, 29 jun 2015. Disponível em: http://www.planalto.gov.br/ccivil_03/_ato20152018/2015/Lei/L13140.htm\#art47 [ Acesso em 24.set.2017].

12. Gil AC. Métodos e Técnicas de Pesquisa Social. 6.ed. São Paulo: Editora Atlas; 2008. 
13. Brasil. Constituição da República Federativa do Brasil. 5 de outubro de 1988.

Brasília. Disponível em:> http://www.planalto.gov.br/ccivil_03/constituicao/constituicao.htm [Acesso em 15.ago.2017].

14. Brasil. Lei no 8.625, de 12 de fevereiro de 1993. Institui a Lei Orgânica Nacional do Ministério Público, dispõe sobre normas gerais pra a organização do Ministério Público dos Estados e dá outras providências. Brasília. 15 fev 1993. Disponível em http://www.planalto.gov.br/ccivil_03/leis/L8625.htm [Acesso em 15.ago.2017].

15. Brasil. Lei Complementar no 75, de 20 de maio de 1993. Dispõe sobre a organização, as atribuições e o estatuto do Ministério Público da União. Brasília. 21 maio 1993. Disponível em http://www.planalto.gov.br/ccivil_03/leis/lcp/lcp75.htm [Acesso em 15.ago.2017].

16. Brasil. Conselho Nacional do Ministério Público. Resolução no 174, de 4 de julho de 2017. Disciplina, no âmbito do Ministério Público, a instauração e a tramitação da Notícia de Fato e do Procedimento Administrativo. Diário Eletrônico do CNMP, Caderno Processual, p. 3-5. Brasília, 21 jul 2017. Disponível em http://www.cnmp.mp.br/portal/images/Resolucoes/Resolu\%C3\%A7\%C3\%A3o-174.pdf [Acesso em 14.out.2017].

17. Brasil. Conselho Nacional do Ministério Público. Resolução ํㅜ 23, de 17 de setembro de 2007. Regulamenta os artigos 6을 inciso VII, e 7을 inciso I, da Lei complementar $n^{\circ}$ $75 / 93$ e os artigos 25, inciso IV, e 26, inciso I, da Lei no 8.625/93, disciplinando, no âmbito do Ministério Público, a instauração e tramitação do inquérito civil. Diário de Justiça. Brasília, 7 nov 2007. Disponível em http://www.cnmp.mp.br/portal/images/Resolucoes/Resolu\%C3\%A7\%C3\%A3o-0231.pdf [Acesso em 14.out.2017].

18. Brasil. Conselho Nacional do Ministério Público. Resolução $n^{\circ}$ 82, de 29 de fevereiro de 2012. Dispõe sobre as audiências públicas no âmbito do Ministério Público da União e dos Estados. Diário Oficial da União. Brasília, 9 abr 2012. Disponível em http://www.cnmp.mp.br/portal/images/Resolucoes/Resolu\%C3\%A7\%C3\%A3o-0821.pdf [Acesso em 14.out.2017].

19. Brasil. Conselho Nacional do Ministério Público. Resolução n 179, de 26 de julho de 2017. Regulamenta o $6^{\circ}$ o do art. 5ํ da Lei no 7.347/1985, disciplinando, no âmbito do Ministério Público, a tomada do compromisso de ajustamento de conduta. Diário Eletrônico do CNMP. Brasília, 8 set 2017. Disponível em http://www.cnmp.mp.br/portal/images/Resolucoes/Resolu\%C3\%A7\%C3\%A3o-179.pdf [Acesso em 14.out.2017].

20. Brasil. Lei no 7.347, de 24 de julho de 1985. Disciplina a ação civil pública de responsabilidade por danos causados ao meio-ambiente, ao consumidor, a bens e direitos de valor artístico, estético, histórico, turístico e paisagístico e dá outras 
providências. Diário Oficial de União. Brasília, 25 jul 1985. Disponível em:

http://www.planalto.gov.br/ccivil_03/leis/L7347orig.htm [ Acesso em 12.out.2017].

21. Brasil. Lei no 8.078 , de 11 de setembro de 1990. Dispõe sobre a proteção do consumidor e dá outras providências. Diário Oficial da União. Brasília, 12 set 1990. Disponível em: http://www.planalto.gov.br/ccivil_03/leis/L8078.htm [Acesso em 23.set.2017].

22. Almeida DAR, Pantoja FM, Andrade JL. Fundamentos. In Hale D, Pinho HDB, Cabral TNX, organizadores. O marco legal da mediação no Brasil: comentários à lei № 13.140, de 26 de junho de 2015. São Paulo: Atlas; 2016. p. 34-90.

23. Tartuce F. Mediação nos conflitos civis. 2.ed. Rio de Janeiro: Forense; São Paulo: Método; 2015. p. 42, 43, 73.

24. Meireles DRS, Marques GPY. Mediadores. In Hale D, Pinho HDB, Cabral TNX, organizadores. O marco legal da mediação no Brasil: comentários à lei no 13.140, de 26 de junho de 2015. São Paulo: Atlas; 2016. p. 91-128.

25. Souza LM. Mediação de conflitos e administração pública. In Hale D, Pinho HDB, Cabral TNX, organizadores. O marco legal da mediação no Brasil: comentários à lei no 13.140, de 26 de junho de 2015. São Paulo: Atlas; 2016. p. 207-228.

26. Cabral AP, Cunha LC. Métodos alternativos de solução de conflitos - ADR: negociação direta ou resolução colaborativa de disputas (collaborative law): mediação sem mediador. Revista de Processo. 2016; 259:471-489. Disponível em http://www.mpsp.mp.br/portal/page/portal/documentacao_e_divulgacao/doc_biblioteca/bi bli_servicos_produtos/bibli_boletim/bibli_bol_2006/RPro_n.259.18.PDF; [Acesso em 15.out.2017].

27. Oliveira MHM. Considerações sobre os direitos transindividuais. Cognitio Juris. João Pessoa. Ano I, Número 2, agosto 2011, disponível em <http://www.cognitiojuris.com/artigos/02/06.html>. [Acesso em 8.out.2017].

28. Didier Júnior F, Zaneti Júnior H. Curso de Direito Processual Civil: processo coletivo. 10.ed. Salvador: Editora JusPodivm; 2016.

29. Rodrigues GA. Ação civil pública e termo de ajustamento de conduta. 3.ed. Rio de Janeiro: Editora Forense; 2011. p. 30.

30. Gidi A. Coisa Julgada e litispendência em ações coletivas. São Paulo: Saraiva; 1995.

31. Gotti A. Judicialização do direito à saúde e insuficiência dos mecanismos tradicionais de resolução de conflitos. In Bucci MPD, Duarte CS, coordenadoras. Judicialização da saúde: a visão do Poder Executivo. São Paulo: Saraiva; 2017. p. 174-202. 
32. Souza LM. Mediação de Conflitos Coletivos: a aplicação dos meios consensuais à solução de controvérsias que envolvem políticas públicas de concretização de direitos fundamentais. Belo Horizonte: Forum; 2012.

33. Gavronski AA. Potencialidades e limites da negociação e mediação conduzida pelo Ministério Público. In Brasil, Conselho Nacional do Ministério Público. Manual de negociação e mediação para membros do Ministério Público. 2.ed. Brasília: CNMP; 2015. p. 143-163.

34. Cambi E. Neoconstitucionalismo e neoprocessualismo: direitos fundamentais, políticas públicas e protagonismo judiciário. São Paulo: Editora Revista dos Tribunais; 2009. p. 489.

35. Godinho RR. A proteção processual dos direitos dos idosos: Ministério Público, tutela de direitos individuais e coletivos e acesso à justiça. Rio de Janeiro: Lumen Juris; 2007. p. 76-77.

36. Ribeiro CVA. Funções administrativas e discricionárias do Ministério Público. In: Ribeiro CVA, organizador. Ministério Público: reflexões sobre princípios e funções institucionais. São Paulo: Atlas; 2010. p. 339-356.

37. Souto MJV. A era da consensualidade e o Ministério Público. In: Ribeiro CVA, coordenador. Ministério Público: reflexões sobre princípios e funções institucionais. São Paulo: Atlas; 2010. p. 286-304.

38. Marques FA. Discricionariedade administrativa e controle judicial da administração. In: Salles, CA, organizador. Processo Civil e interesse público: o processo como instrumento de defesa social. São Paulo: Editora Revista dos Tribunais, Associação Paulista do Ministério Público; 2003. p. 191-198.

\section{Como citar este artigo:}

Matos LV. O papel do Ministério Público na autocomposição de conflitos sanitários transindividuais. Revista Cadernos Ibero-Americanos de Direito Sanitário. 2017 out./dez, 6(4):70-90. 